\title{
Measurement of matric suction using tensiometric and axis translation techniques.
}

\author{
MARINHO, F.A.M. \\ Universidade de São Paulo, Brasil
}

TAKE, W.A.

Queen's University, Canada

TARANTINO, A

Università degli Studi di Trento, Italy

\begin{abstract}
Experimental equipment for the measurement of matric suction in unsaturated soils using hydraulic tensiometers and the axis translation technique share a common working principle; that is, the measurement of a pressure differential across a high air entry porous ceramic. In this paper, the current state of the art in these two suction measurement techniques is presented and discussed together with the underlying physics thereby giving the reader the necessary basis to use and interpret the results obtained from those two techniques.
\end{abstract}

\section{Introduction}

Measurement of negative pore-water pressure is of primary importance in the analysis and prediction of unsaturated soil behaviour. Conventional tensiometers (Stannard, 1992) can measure negative water pressures only in the range from 0 to $80 \mathrm{kPa}$ and their application is therefore quite limited. In the early 1990's, Ridley and Burland (1993, 1995) first developed high-capacity tensiometers capable of measuring negative water pressures down to $-1500 \mathrm{kPa}$. Since then, a number of instruments have been developed and successfully used in laboratory and field experiments (Ridley et al. 1997; Take and Bolton, 2003; Cunnigham et al. 2003; Oliveira and Marinho, 2003; Tarantino and Tombolato, 2005). Nonetheless, the spread of this type of instrument is still fairly limited. Development of 'homemade' and commercial high-capacity tensiometers is hampered by a lack of knowledge of basic principles, suitable design and experimental techniques. Although state-of- 
the-art reports on tensiometric measurement have already been presented in the literature (Ridley and Wray, 1996; Tarantino, 2004), many points are worthy to be addressed in the light of the most recent findings.

Tensiometric technique shares with axis translation technique a common working principle; that is, the measurement of a pressure differential across a high air entry porous ceramic. For this reason, these two suction measurement techniques are presented and discussed together to underline their similarities (saturation procedures, the need for intimate contact, air diffusion, air entry, etc) and their differences (absolute positive and negative pressures, cavitation, etc.) thereby giving to the reader the necessary basis to use and interpret the results obtained from those two techniques. The axis-translation technique as a system to control suction in unsaturated soil testing is discussed in detail elsewhere in this issue (Vanapalli et al., Ibid.)

\section{Basic concepts}

\subsection{Gauge vs. absolute pressure}

In most Geotechnical Engineering applications, fluid pressures are typically thought of and reported in terms of gauge pressure, i.e. relative to atmospheric pressure. Thus, pressure reduced to a value below atmospheric, is referred to as negative if the fluid is water or a vacuum if the fluid is air. However this definition of pressure, although useful in engineering practice, is of limited value in the quantification of phase relationships as these are defined in terms of absolute pressure. When referring to pressure in absolute terms, the zero pressure origin is defined as a total vacuum, the atmospheric pressure at sea-level is approximately $101.6 \mathrm{kPa}$, positive water pressures imply compression, and negative water pressures imply that the water is being held in tension (i.e. it is being stretched).

\subsection{Surface tension, contact angle, and hysteresis}

The physics of the contact angle hysteresis is useful to illustrate, at least in a qualitative way, the mechanisms likely to control cavitation in high suction tensiometer. It also provides a conceptual justification for the axis-translation technique.

The surface tension, $T$, of a liquid is the force per unit length acting in the plane of the surface of a liquid in contact with its own vapour resulting from the unsymmetrical force field at a liquid surface. Consider a liquid in equilibrium with its own vapour and a solid surface as shown in Figure 1a. The angle between the solid surface and the gas-liquid interface at the three-phase line of contact is defined 
as the contact angle, $\theta$ (measured through the liquid). The contact angle is the result of a balance between the cohesive forces in the liquid and the adhesive forces between solid and liquid. A liquid with a contact angle less than $90^{\circ}$ (e.g. water) is said to wet a surface as a drop of the liquid tends to spread when placed on a solid surface.

The phenomena of capillarity occurs in fluid-surface systems of contact angles less than $90^{\circ}$. In these cases, the contact angle of the system causes the liquid to rise in small diameter pores such as the idealised circular pore of Figure 1b. The water pressure, $u_{w m}$, at the back of the meniscus can be calculated by considering the vertical force equilibrium at the air-water interface:

$u_{w m}=u_{a}-\frac{4 T \cos \theta}{d}$

where $d$ is the diameter of the capillary and $u_{a}$ is the air pressure. Since $\cos \theta>0$, water pressure at the back of the meniscus, $u_{\mathrm{wm}}$, is less than air pressure. As a result, the meniscus will rise in the capillary until hydrostatic conditions are established. Let us assume that air pressure is atmospheric (i.e. $101.6 \mathrm{kPa}$ absolute pressure), $\mathrm{T}=0.072 \mathrm{~N} / \mathrm{m}$ (air-water surface tension at $20^{\circ} \mathrm{C}$ ) and $\theta=0$. Equation 1 indicates that the absolute water pressure is zero when $d=2.8 \mu \mathrm{m}$ and becomes more and more negative as the radius of the pore decreases. As will be seen in the next section, the magnitude of this negative pressure is limited by the phase relationships of the pore fluid and the phenomenon of cavitation.

Gibbs (1948) showed that one and only one stable contact angle exists for a given system for the case of smooth, homogenous and nondeformable solids. In practice, however, this is rarely, if ever, the situation. If these assumptions are removed, it can be shown within the framework of classical thermodynamics that many different stable angles exist for a given system, i.e. the contact angle exhibits hysteresis (Johnson and Dettre, 1969). The concept of contact angle hysteresis can perhaps be best explained by considering the following example. As shown in Figure 2a, a drop of liquid can be placed on surface and is progressively tilted until the drop rolls off the plate. At a small inclination, the contact angles at the leading and trailing edge of the drop will increase and decrease respectively and prevent the drop periphery from moving. This will continue until a limit condition is attained when these angles become the advancing and receding angles, $\theta_{\mathrm{a}}$ and $\theta_{\mathrm{r}}$ respectively, at which point the drop will roll off the plate. Thus, a number of macroscopic stable contact angles exist for a given system in the range from $\theta_{\mathrm{r}}$ to $\theta_{\mathrm{a}}$.

The hysteresis of the contact angle can be produced by surface roughness. Consider once again a drop on a tilting plate, this time with a rough surface (Figure 
2b). Even though the leading and trailing edges of the drop both meet the solid with the same intrinsic angle, $\theta_{0}$, the macroscopic angles measured with respect to the tilt plane are different at the front and back of the drop.

Surface heterogeneity can also cause contact angle hysteresis. If, in our example the tilting plate is heterogeneous (Figure 2c), the leading edge of the drop will tend to stop at the boundaries of the high-contact-angle regions. The advancing angles may then be associated with the intrinsic angle of the high-contact-angle regions, whereas the receding angles are controlled by the low-contact-angle regions (Johnson and Dettre, 1969).

\subsection{Stable and metastable states of water}

The phase diagram for water (Figure 3) is reported in undergraduate textbooks as the diagram defining whether water will take the form of a solid (ice), liquid, or gas (vapour) at a given temperature and pressure. To explore the phase diagram, consider a closed system containing liquid water at the temperature and pressure of point A. If pressure is reduced isothermally, the liquid-gas equilibrium line is eventually reached at point $\mathrm{B}$, where bubbles normally form in the liquid. In order for the pressure to be further reduced to Point $\mathrm{C}$, only vapour must be present in the system.

Since absolute vapour pressure can not be negative, the phase diagram shown in Figure 3 seems to suggest that also the minimum absolute liquid pressure (point B) can not be negative. This has led to the common misassumption that liquids can not withstand absolute negative pressures. The phase diagram for water shown in Figure 3 only represents the stable states for water. However, other states are possible (including water under negative pressure) which do not violate the principles of classic thermodynamics. To elucidate this point, it is useful to represent the phase diagram of water in the pressure-molar volume plane (Figure 4a). If liquid water at point $\mathrm{A}$ is subjected to isothermal expansion, pressure will decrease according to the equation of state of the fluid. At point $B$, liquid water will transform into vapour water at constant pressure (and temperature). As point $\mathrm{B}^{\prime}$ is reached, liquid water will no longer be present in the system and further expansion will bring water vapour to point $\mathrm{C}$ according to the equation of state of water vapour.

A question that might be asked is whether liquid water in D may exist in (meta)stable state if no gas is present in the system. To answer this question it may be useful to consider the equation of state of fluids proposed by van der Waals:

$\left(p+\frac{a}{v^{2}}\right)(v-b)=R T$ 
where $p=$ pressure, $v=$ molar volume, $R=$ universal gas constant, $T=$ absolute temperature, $a$ and $b$ the van der Waals' constants depending on the type of fluid. This equation, though quantitatively inaccurate, provides a simple picture of vapour-liquid equilibrium (De Benedetti, 1996). With respect to the equation of ideal gas law, van der Waals' equation accounts for the intermolecular repulsive and attractive forces and describe the continuity between gaseous and liquid states (Rowlinson, 1988). If the temperature is high enough that the average kinetic energy of a molecule greatly exceeds the molecular attraction the fluid behaves as a gas. If temperature is low enough, attractive forces prevail and the fluid behaves as a liquid. Van der Waals' isotherms are plotted in Figure 5 for liquid water at five different temperatures.

Using Gibbs' general criteria of equilibrium, it can be shown that the fluid along the isotherm is stable when the fluid isotropic compressibility, $K_{\mathrm{T}}$, is positive (De Benedetti, 1996). More thermodynamics is required to explain this stability criterion which has, however, a clear intuitive meaning. Equilibrium is stable if pressure increases when the substance is compressed isothermally ( $K_{\mathrm{T}}$ is positive). In this case, the increase in fluid pressure will counterbalance the external applied pressure. On the other side, the equilibrium is unstable if pressure decreases when the substance is compressed isothermally ( $K_{\mathrm{T}}$ is negative), because the fluid pressure cannot counterbalance the external applied pressure. According to this stability criterion, the dashed part of the van der Waals' isotherms (DE) in Figure 4a represents unstable states, i.e. impossible states for the fluid. On the other side, states along $\mathrm{BD}$ and $\mathrm{EB}^{\prime}$ are stable states, as stability criteria are satisfied. These states are however called metastable because a gas phase will rapidly separate in the liquid if an amount of gas is present in the liquid (see Figure 4b, path M-M').

This can be shown in Figure 4b, where the Helmholtz energy is plotted against molar volume for isothermal paths. Calculation of Helmoltz energy variation at constant temperature can be found in De Benedetti (1996). According to Gibbs' general criteria of equilibrium, a system at constant volume, temperature, and mass will move to states of minimum Helmholtz energy (Gibbs, 1948; Berry et al., 1980). Helmholtz energy along the theoretical isotherm BD is higher than Helmholtz energy along the coexistence line BB'. If the liquid water is at point $\mathrm{M}$ and gas nuclei are present in the system, liquid water will partially transform into vapour water to bring the system to a lower Helmholtz energy (M'). However, if the system were ideally free of any gas, the water would remain liquid in M. The locus passing through the minimum and maximum of the isotherms in Figure 4a that separate the region of unstable states from the one of metastable states is called the spinodal. 
The van der Waals' isotherms for water are plotted in Figure 5 with the constant $\mathrm{a}$ and b calculated from the critical constants (Alberty, 1987). This figure shows that liquid water at $20^{\circ} \mathrm{C}$ can remain in a metastable state down to a pressure slightly greater than $100 \mathrm{MPa}$. This pressure would be the theoretical tensile strength of water according to the van der Waals' equation for fluid. This value seems to capture the correct order of magnitude of liquid water tensile strength although different values can be calculated using a more accurate equation of state.

\subsection{Homogeneous and heterogeneous cavitation}

Despite pure water having a high theoretical tensile strength on the order of $100 \mathrm{MPa}$, experimental studies have for years failed to approach this value. For example, prior to the 1970's experimental determinations of the maximum attainable tensile stress in water ranged approximately from 1.3 to $27 \mathrm{MPa}$ (Knapp et al., 1970). However more recently, Zheng et al. (1991) were able to measure a tensile stress of $140 \mathrm{MPa}$ in a single crystal of water, a value believed to be very close to the maximal tension that water can sustain. This wide variation in experimental data can be explained by imperfections that lead to instability and transition to points such as $\mathrm{M}^{\prime}$ in Figure 4.

Imperfections can typically occur in two forms. The thermal motions within the liquid form temporary, microscopic voids that constitute the nuclei necessary for rupture and growth to macroscopic bubbles. This is termed homogenous nucleation. The tension necessary to cause homogenous nucleation in pure water can be estimated by a simple calculation (Brennen, 1995). Let us assume that the ephemeral vacancy caused by thermal motions has diameter equal to the intermolecular distance of water $(d=0.35 \mathrm{~nm})$ and that such a vacancy rapidly saturates with water vapour, having absolute pressure equal to the vapour pressure of water $\left(p_{\mathrm{v}}=2.3 \mathrm{kPa}\right.$ at $\left.20^{\circ} \mathrm{C}\right)$. The absolute water pressure necessary to cause the expansion of the cavity can then be calculated using Laplace's equation (derived in a similar way as Equation 1):

$p_{w}=p_{v}-\frac{4 T}{d}=-823 M P a$

This value, however, has never been measured in laboratory experiments. More often, major weakness occurs at the boundary between the liquid and the solid wall of the container or between the liquid and small particles suspended in the liquid. Rupture that occurs at these sites it is termed heterogeneous nucleation. This latter type of cavitation is of interest in tensiometer measurement.

The concept of heterogeneous cavitation will be further developed by considering the behaviour of a water reservoir bounded by a saturated ceramic filter 
(i.e. a tensiometer) as shown in Figure 6. In this example, the saturation of the container system is imperfect - as shown in enlarged inset of Figure 6a, there exists an idealised crevice on the container boundary which contains a finite quantity of air and water vapour. If the water pressure in the reservoir is dropped, the pressure within the crevice must also decrease, thereby increasing the gas volume according to its equation of state (Figure 6b). If the water pressure in the sensor is dropped further, or if the volume of gas increases due to diffusion, a critical contact angle will eventually be reached which is the higher between the crevice opening angle and the receding contact angle (Mongiovì and Tarantino, 2002). At this point, the stability of the growing air cavity cannot be maintained and it will be pulled from the crevice in a form of free cavity (Figure 6c). An example of heterogenous cavitation triggered by air trapped in wall crevices is observed in a glass of champagne where diffusion of carbon dioxide into trapped air-filled crevices causes steady streams of bubbles to form on the sides of the glass (Balibar, 2002).

The newly formed free cavity is unstable and will almost instantaneously expand to occupy a large part of the water reservoir. As the gas pressure in the cavity is initially very close to the water vapour pressure, the tensiometer will read an absolute pressure close to zero and a gauge pressure of about $-100 \mathrm{kPa}$. This rapid jump to approximately $-100 \mathrm{kPa}$ gauge pressure is therefore a clear indication of cavitation having occurred in the system. It must be noted that heterogeneous cavitation in the tensiometer may also be triggered by gas nuclei entrapped in the porous ceramic rather than in the container wall as discussed by Tarantino and Mongiovì (2001) and Tarantino (2004).

\subsection{Air-entry}

The air-entry value of a saturated porous solid is the gas-minus-liquid pressure differential which must be applied to the initially liquid-saturated material to initiate advective gas transport through the material. This ability results from menisci that form at the saturated-material boundary. The air-entry value can then be theoretically calculated by considering the force equilibrium at the air-water interface in a single narrow pore at the material outer surface. This leads to Equation 1 indicating that the magnitude of air-water pressure differential at breakthrough will be inversely proportional to the pore diameter. Therefore porous ceramics are typically used for this application as they can be made with uniform, highly controlled pore size distributions. The typical pore sizes used in tensiometers ranges from $6 \mu \mathrm{m}$ to $0.16 \mu \mathrm{m}$ corresponding to nominal air-entry values of $50 \mathrm{kPa}$ to $1500 \mathrm{kPa}$, respectively. The actual air-entry value is typically provided by the manufacturer by measuring the air pressure applied to one side of the ceramic necessary to cause bubbling on the other side (bubbling pressure). Possible 
differences between air-entry value and bubbling pressure have been discussed by Tarantino (2004).

\section{Measurement of matric suction using tensiometers}

\subsection{Evolution of the tensiometer}

Occasionally in the literature, users of tensiometers would record pressures below $-100 \mathrm{kPa}$, but it was not until the work of Ridley (1993) was published that the geotechnical community became aware of the possibility of creating a tensiometer which can reliably measure negative water pressures down to $1500 \mathrm{kPa}$. This work created a new class of tensiometer, known as the high capacity tensiometer (HCT), which took advantage of available higher air entry value ceramics $(0.3,0.55,1.5 \mathrm{MPa})$ and was designed to permit the water reservoir of the device to achieve true tensile pressures.

\subsection{HCT Design}

The HCT design of Ridley (1993) and that of those that followed after it was designed to delay heterogeneous cavitation within the water contained within these devices. This involves minimising the volume and surface area of the internal water reservoir to reduce the absolute number of possible nucleation sites, with the aim being to be statistically less likely to suffer from unpredictable tension breakdowns (Ridley, 1993). The second modification, introduced by Ridley and Burland (1995), involves the elimination from the design of the tensiometer any materials which are particularly good sources of nucleation sites, such as o-rings and elastomers. The influence of elastomers on the behaviour of HCT's has been demonstrated by Take (2003). In an early version of the tensiometer developed at Cambridge University by Take (2003), an elastomer was used in the design to isolate the pressure sensor from externally applied effective stresses. Despite measuring tensions in excess of $100 \mathrm{kPa}$, these early prototypes illustrated a wide variation of maximum measurable suctions ranging from $270 \mathrm{kPa}$ to $480 \mathrm{kPa}$. Once the elastomer was removed from the design of the sensor, nucleation occurred only at tensions greater than the nominal air entry value. This variation in maximum attainable tension was also reported in the observations of Guan and Fredlund (1997) in which an o-ring was also used in the design.

The schematics of several HCT reported in the literature are presented in Figure 7, including the HCT developed at Imperial College (Ridley and Burland, 1993; 1995), University of Saskatchewan (Guan and Fredlund, 1997), University of São Paulo (Marinho and Pinto, 1997), University of Trento (Tarantino and Mongiovi, 
2002), Massachusetts Institute of Technology (Sjoblom, 2000; Toker, 2002), Cambridge University (Take and Bolton, 2003) and University of Durham (Lourenço et al., 2006). Also included in Figure 7, is the Druck PDCR-81, a commonly used miniature pore pressure transducer which has sometimes been modified to act as a tensiometer. As can be seen in Figure 7, all of these devices share a common design, with the only slight modification being in the Cambridge and the Druck devices which are intended for burial within soil, and as such, are designed to isolate the internal pressure sensing diaphragm from the effective stresses exerted on the outer case of the device. The gap between the pressure sensor and the outer shell ensures that any strains in the outer casing of the device are not transferred to the pressure sensing diaphragm, thus creating an apparent pressure change. This issue is obviously only relevant for HCT's placed in a stress field, and not in the measurement of matric suction in soil samples.

\subsection{Saturation}

Although the design of HCT is an important consideration, design alone cannot ensure the measurement of tensile water pressures. Indeed, it can be argued that the most important factor determining the success or failure of tensiometer measurements relates to the saturation and preconditioning of the water contained within the porous filter and reservoir of the device. The process of saturation of tensiometers has been examined by Take and Bolton (2003) following the work of Bishop and Eldin (1950) and Lowe and Johnson (1960). This work is based on the assumption that the air-water interface is flat and indicates that air within a porous filter of initial degree of saturation, $\mathrm{S}_{\mathrm{i}}$, and at an initial absolute pressure of $\mathrm{P}_{\mathrm{i}}$, will compress according to Boyle's law when pressure $\Delta \mathrm{P}$ is applied, allowing water to enter pores once occupied by air if the volume of the porous ceramic is assumed constant. Henry's law dictates that the higher pressure will also result in additional air being dissolved into the pore water. The pressure change, $\Delta \mathrm{P}$, required to increase the degree of saturation of a porous element to its final saturation value, $\mathrm{S}$, has been shown to be:

$\Delta P=P_{i} \frac{\left(S-S_{i}\right)(1-H)}{1-S(1-H)}$

where, $\mathrm{H}$ is Henry's constant which is approximately $0.02 \mathrm{ml}$ of air per $\mathrm{ml}$ of water at room temperature.

Since full saturation is required in the tensiometer (i.e. $S=1$ ), the theoretical magnitude of applied pressure required to perform this task is a function of both the initial absolute pressure of the air in the voids and the initial degree of saturation of the porous disk. Therefore, if the initial absolute pressure is dropped close to $0 \mathrm{kPa}$ 
absolute in a tensiometer which is as dry as possible, the pressure required for saturation can be minimized. Thus, Equation 4 provides a theoretical justification for a two-stage saturation process in which the tensiometer is first introduced to water under a high vacuum before a large positive pressure is applied. Such a process has been experimentally determined by researchers (e.g. Ridley and Burland, 1999) to give the best results, with Tarantino and Mongiovì (2002) and Take and Bolton (2003) giving particular attention to the role of initial dryness of the porous filter by proposing a two chamber saturation to evacuate the tensiometer in the absence of water.

Indeed, pressure $\Delta \mathrm{P}$ given by Equation 4 is sufficient to dissolve most but not all the air in the ceramic and in the reservoir. This is because the air-water interface of air cavities retracting into the small pores of the ceramic and crevices on the reservoir walls is no longer flat but must become concave on the water side. The meniscus is then capable of sustaining high water pressures, thus preventing air dissolution. Figure 8a illustrates an ideal conical crevice. The depth $h$ of the air cavity depends on the water pressure $p_{\mathrm{w}}$, gas pressure $p_{\mathrm{g}}$, the advancing contact angle $\theta_{\mathrm{a}}$ and crevice opening $\varphi$ as follows (Mongiovì and Tarantino 2002):

$h=\frac{2 T \cos \left(\theta_{a}-\varphi\right)}{\tan \varphi\left(p_{g}-p_{w}\right)}$

Equation 5 suggests that the application of a positive water pressure will cause $h$ to decrease, and hence the amount of air that is dissolved in water to increase. If, on return to atmospheric pressure, a significant quantity of the recently dissolved air does not return to the cavity, but rather, is preferentially exsolved where the water meets the free air (Ridley and Wray, 1996), the amount of gas within the total system will be reduced. Thus, a higher water tension will be required to initiate nucleation at these nucleation sites than had existed previously. This is the reason why high capacity tensiometers are conditioned by the application of large positive water pressures prior to measurement (often called pre-pressurisation).

Equation 5 also suggests that depth $h$ can reduce to zero (i.e. the air cavity completely dissolves) only if $\theta_{a} \leq 90+\varphi$. The meniscus remains convex on the water side and will not be able to sustain a water pressure $p_{\mathrm{w}}$ greater than gas pressure $p_{\mathrm{g}}$. In contrast, if $\theta_{\mathrm{a}}>90+\varphi$, the meniscus can reverse its curvature and become concave on the water side. According to Equation 5, the air cavity will not dissolve regardless of the water pressure applied and its depth $h$ will increase as the advancing contact angle $\theta_{\mathrm{a}}$ increases. According to Harvey et al. (1944), air cavities that remain entrapped in crevices are likely to trigger cavitation when pressure is reduced and the meniscus curvature is reversed (Figure 8b). 
The cavitation nuclei that remain undissolved upon pressurization can be 'extracted' by cycles of cavitation followed by large positive pressures according to the mechanism suggested by Tarantino and Mongiovì (2001). This saturation technique is particularly important in HCT's with very high air entry value ceramic filters (e.g. 1.5 MPa), as it has been observed that one application of high positive pressures is not sufficient to dissolve sufficient trapped gas within a HCT (e.g. Tarantino and Mongiovì, 2001) but cycles of cavitation followed by pressurisation can significantly improve measurement duration and maximum sustainable tension (Tarantino, 2004). In lower air entry value porous filters (e.g. 0.1 MPa, 0.3 MPa), a single pressurisation event has been observed by Take and Bolton (2003) to be sufficient for accurate measurement.

The duration of application of high pre-pressurisation pressures is another factor that may affect saturation of the porous filter. Intuitively, the higher the duration of pressurisation, the higher should be the saturation of the ceramic filter and, hence, the measurement duration and maximum sustainable tension. However, Tarantino \& Mongiovì (2001) report the response of one Imperial College tensiometer after 1 year saturation at $4 \mathrm{MPa}$. During this period, the tensiometer remained continuously stored in the saturation chamber since not in use. The first measurement recorded by this tensiometer, after removal from the saturation chamber showed cavitation occurred after just some seconds at a tensile stress of about $650 \mathrm{kPa}$. This poor response was unexpected as the tensiometer was assumed to be fully saturated after such a long period of pressurisation.

After a single cycle of cavitation followed by pressurisation, the tensiometer was capable of measuring a remarkable suction, even much higher than the nominal air entry value of the porous ceramic $(2600 \mathrm{kPa})$. This would suggest that cycles of cavitation/pressurisation are more effective than pressurisation itself. However, more data would be needed to corroborate such an assumption.

\subsection{Measurement range}

If saturated sufficiently, it has been shown by Ridley and Burland (1995) that the maximum sustainable suction of a HCT is strictly a function of the air entry value of the ceramic. This is because the highest air entry value of currently available ceramics is nominally $1500 \mathrm{kPa}$, whilst the tensile strength of water is approximately two orders of magnitude greater. As discussed by Take and Bolton (2004), caution should be exercised when interpreting observations of suction in excess of the nominal air entry value. The observed suction in this case could either be the true value or could be an artefact of the ongoing process of air entry. Thus, the reliable measurement range of a HCT should be taken as the maximum full 
scale positive pressure of the pressure sensitive diaphragm to a negative value corresponding to the magnitude of the porous filter's air entry value.

\subsection{Contact}

If good contact is not established between the soil pore water and the porous filter of the HCT, misleading observations of matric suction will be obtained. The most drastic example is of a tensiometer with no contact. In this scenario, the device will quickly desaturate as it attempts to come into moisture equilibrium with the air in the gap between the tensiometer and the soil surface. The measured suction will therefore not be representative of that found in the soil. This issue has been overcome by placing a small amount of slurry on the tip of the tensiometer to ensure intimate contact between the porous filter and the surrounding soil. It is recommended to prepare the slurry at a water content near the liquid limit, preferably using the fines of the same material in which the tensiometer is going to be installed. It should be noted that the response time of the HCT will depend on the degree of saturation and unsaturated permeability of the soil, but also on the water content of the slurry used to improve the contact. If the slurry is prepared excessively wet of the liquid limit, the addition of this extra moisture into the system will lengthen the time required for moisture equilibrium to occur with the native soil (e.g. Boso et al. 2004; Oliveira and Marinho, 2008).

\subsection{Osmotic effect of the porous ceramic}

Marinho \& Chandler (1994) suggested that the fine porous stone interface could prevent the passage of ions from the soil water into the tensiometer reservoir. As a result, an osmotic suction could develop in the tensiometer because of the concentration gradient. The tensiometer would then measure a value ranging between matric suction and total suction.

A simple test was carried out by Tarantino (2004) to verify whether porous ceramic has an osmotic effect, i.e. is capable of retaining ions dissolved in soil water. The tensiometer was immersed in 4 different $\mathrm{NaCl}$ solutions having osmotic suction of $216,432,650$, and $880 \mathrm{kPa}$. The tensiometer was kept in salt water for about $15 \mathrm{~min}$ and then replaced in free water for other $15 \mathrm{~min}$ prior to testing the subsequent $\mathrm{NaCl}$ solution. The pressure recorded by the tensiometer did not change throughout the test, indicating that the high air entry ceramic does not have an osmotic effect, at least for this type of solute. However, it is possible that osmotic effects could arise for different type of solutes. 


\subsection{Challenges}

\subsubsection{Interpretation}

Unlike the measurement of positive pore water pressures, the measurement of negative water pressures brings with it some unique challenges - particularly in the interpretation of suction data, and in the long term measurement of soil suction. When measuring suctions using tensiometers, it is not always apparent when the tensiometer has stopped recording the true value of suction. Indeed, it has been argued that the biggest challenge associated with tensiometer measurement is how to discriminate a good measurement from a bad one (Tarantino, 2004). This challenge has been rigorously demonstrated by Take and Bolton (2003) in which tensiometers were saturated to various degrees of saturation. To illustrate this problem, the behaviour of a tensiometer having been saturated to a degree of saturation of 0.77 has been reproduced as Figure 9. The tensiometer was placed in water and then subjected to known values of negative water pressure. As shown in Figure 9, the device initially correctly measures the suction and continues to do so until the applied pressure drops below $-65 \mathrm{kPa}$ (point $\mathrm{B}$ ), at which point the device becomes completely detached from reality. This demonstration illustrates the high probability for erroneous tensiometer measurements if the device is not properly saturated or has been allowed to desaturate in-situ. Other examples of erroneous measurement occurring when ceramic disk is not adequately saturated are provided by Tarantino (2004). Strategies to overcome this issue include only relying on highly qualified personnel to saturate, install and monitor tensiometers; using two HCT's to check the internal consistency of suction observations by using two or more tensiometers simultaneously placed on the same sample (Tarantino and Mongiovì, 2001); identifying indicators of adequate saturation of the ceramic disk (Tarantino, 2004); or using tensiometers paired with other indirect methods of suction measurement, again to check for consistency (Whalley et al., 2006).

\subsubsection{Long term measurement}

The second major challenge currently facing HCT's relates to their ability to obtain long term measurements. Although the conditioning process of applying high positive water pressures can reduce the amount of gas trapped in crevices, it can never completely eliminate it. It has already been noted that the process of diffusion can slowly lead to bubble growth over the long term. Thus, the stabilisation afforded by the conditioning process must be viewed as temporary the water held in the reservoir is metastable and all tensiometers will inevitably experience nucleation. However, no experimental data currently exists to 
adequately predict the length of time a tensiometer can remain operational at high suctions; such is the variability in the instability of tension breakdown. This topic is a current area of research.

Measurements at relatively high suction $(800-900 \mathrm{kPa})$ may last several days. Cunningham et al. (2003) report measurement of $s=850 \mathrm{kPa}$ for 8 days and suction measurement in the osmotic oedometer presented by Tarantino \& Mongiovì (2000) could last more than 24 days for suctions ranging from 250 to $800 \mathrm{kPa}$.

\section{Measurement of matric suction using the axis translation technique}

\subsection{Principle}

The historical limitation of traditional tensiometer measurements to matric suction values up to $80 \mathrm{kPa}$ led to the development of an alternative laboratory technique (Richards, 1941; 1947) which sidesteps this obstacle by artificially raising the atmospheric pressure experienced by a soil sample. The working principle of this technique is the familiar model of a capillary pore and is reproduced in Figure 10a for the typical case in which the pore is subjected to atmospheric air pressure (i.e. zero gauge pressure) with the water climbing the capillary tube being less than atmospheric. If in the laboratory environment, this same capillary tube was close-ended and subjected to an elevated air pressure, the system would respond as shown in Figure 10b. In Figure 10b, the assumption has been made that the water and solid boundaries are sufficiently incompressible that the curvature of the meniscus interface is not significantly altered (Olson and Langfelder, 1965). If this is true, Equation 2 predicts that the pressure difference $u_{a^{-}}$ $u_{w}$, otherwise known as the matric suction, also does not change. The end result is that the water pressures within the capillary tube have now risen to positive gauge pressures.

The significance of this elevation in water pressure is illustrated in Figure 11 for the measurement of matric suction in unsaturated soils. In Figure 11a, a sample of soil has a matric suction $\left(u_{a}-u_{w}\right)$ in excess of $100 \mathrm{kPa}$. As a result, if this suction is to be quantified a pore water pressure lower than $-100 \mathrm{kPa}$ must be recorded. However, if this same sample is subjected to a large positive air pressure, the water pressure in the soil can be raised to an easily measurable positive gauge pressure. If drainage of the pore water is prevented from the sample, the matric suction in the soil can now be calculated as the difference of these two known pressures. Thus, this technique is referred to as the "axis translation technique" as water pressure has been translated upwards with the air pressure origin and away from the region of metastable states. The above discussion has focussed on the use of the axis 
translation technique to measure suction. This technique may also be used to impose or control suction. This can be accomplished by once again elevating the ambient air pressure within the test cell, but this time controlling also the pore water pressure through a saturated porous filter in contact with the sample (and, hence, allowing water drainage from the sample until equilibrium conditions are obtained.)

\subsection{Design of axis translation test chambers}

The axis translation technique has been used to measure or control suction in triaxial tests, oedometers, and in direct shear tests (e.g. Vanapalli et al., Ibid.). However, by far the most common use of the axis translation technique is in the pressure plate apparatus which is used to determine the soil water retention curve (e.g. Bocking and Fredlund, 1980; Leong et al., 2004; Wang and Benson, 2004, amongst others). If only suction measurement is required, only a sealed chamber which eliminates the possibility of advective air flow and a pore water pressure measurement device is required. If the axis translation technique is applied to impose suction, a highly saturated porous ceramic filter and water reservoir are also required to permit water to enter or leave the sample, as is a procedure to quantify these moisture changes.

\subsection{Saturation}

As was the case in the measurement of matric suction with HCT's, it could be argued that the most important factor determining the success or failure of the axis translation technique relates to the adequate saturation of the porous ceramic disk. For if the ceramic disk is not sufficiently saturated or if bubbles exist in the water reservoir, any measured water volume changes in response to changes in applied matric are meaningless. However, it must be stressed that unlike the HCT the porous ceramic disk and water reservoir are never subjected to negative gauge pressures. As a result, the highly controlled procedures for the conditioning of porous filter - reservoir system to suppress potential cavitation nuclei are typically not followed with the same rigour. However, saturation is typically achieved by broadly the same two stage method: the air chamber above the ceramic is typically evacuated before water is introduced into the cell, followed by pressurising the system to a high positive water pressure. The measurement of the saturated permeability is a good reference for the saturation condition of the system.

\subsection{Measurement range}

The range of axis translation technique to measure or control matric suction is limited by two factors: the maximum air pressure which can be imposed on the system, and the air entry value of the ceramic filter. In practice, the maximum 
measurable suction using the axis translation technique is strictly a function of the air entry value of the ceramic, as the highest air entry value of currently available ceramics is nominally $1500 \mathrm{kPa}$.

\subsection{Contact}

The contact between the pore water and the water of the porous filter is paramount for reliable measurements of suction using the axis translation technique. Poor contact may dramatically increase the drainage time required for equilibrium or may completely eliminate water flow through the ceramic. If there is no continuity of the water in the soil and the water in the ceramic disk, the air pressure will act around the soil sample causing a no flow condition to occur.

\subsection{Challenges}

\subsubsection{Equilibrium time}

The axis translation technique, when used to impose matric suction, does not yield instantaneous results. Even in the absence of soil, the time required for the porous ceramic filter to come into equilibrium with a change in air pressure is on the order of a few minutes, provided the amount of free water on the top of the ceramic disk is small (e.g. Schreiner, 1988). Once a soil sample has been added to the system, the time for equilibrium is extended due to the size and permeability of the soil sample. The ASTM D-6836-02 standard establishes that the equilibrium time should be monitored according to the level of suction and states that for suction less than $500 \mathrm{kPa}$ it is considered equilibrated the system that does not drain any water for at least $24 \mathrm{~h}$, for suction between 500 and $1000 \mathrm{kPa}$ this time should be $48 \mathrm{~h}$ and for suction greater than $1000 \mathrm{kPa}$ no water should be drained for at least 96h. Many authors monitored the equilibrium time behaviour, some of them reporting that the equilibrium is not reached (e.g. Gee at al., 2002) and others reporting that the equilibrium is reached (e.g. Leong et al, 2004). A close look in the data of those papers seems to suggest that the condition established by the ASTM D-6836 is not attained. Thus, one of the challenges associated with the axis translation technique is the potentially long equilibrium time for each imposed suction.

One interesting strategy to overcome this challenge is to adopt the controlled outflow method developed by Lorentz et al. (1991). The method consist in applying air pressure allowing water to drain as in the usual procedure, but closing the water drainage before equilibration is attained. Closing the water drainage before equilibrium is reached will induce an equilibrium of pressure, related to the water content present in the sample. The air pressure applied minus the water pressure 
response is the suction imposed. This method claims to be quicker than the original procedure. Lorentz et al (1991) reported that for sands each point of the soil water retention curve takes between 20 and 40 minutes. This method has been used by many authors with reported success (e.g. Fourie and Papageorgiou (1995); Machado and Dourado (2001); Knight and Kotha (2001)).

\subsubsection{Moisture loss through compressed air lines}

The most intuitive way to apply the elevated air pressure required for the axis translation technique is to use compressed air. However, this could lead to a nonobvious consequence of completely erroneous measurements at low suctions. Figure 12 presents the thermodynamic relation between suction and relative humidity. If a suction of $50 \mathrm{kPa}$ is to be imposed in a soil sample the equivalent relative humidity should be $99.96 \%$. In the case of the air coming from the compressor be at a relative humidity of $99.7 \%$ (which is high and possible) the equivalent suction should be about $400 \mathrm{kPa}$. This difference will cause instability of the system as equilibrium will never be attained. In order to minimize this effect a closed system may be adopted using nitrogen. A numerical analysis of the effect of moisture loss through compressed air lines has been carried out by Romero (2001).

\subsubsection{Air diffusion}

The long equilibrium times associated with the drained axis translation technique make these tests particularly susceptible to the process of air diffusion. Fredlund and Rahardjo (1993) suggest that tests lasting more than one day (without equilibrium attained) will experience air diffusion. As mentioned earlier, if bubbles exist in the water reservoir, measured volume changes are rendered meaningless. Air diffusion through the ceramic disk can be minimised by elevating the water pressure in the reservoir. The rate of accumulation of dissolved air beneath the ceramic disc can be derived by considering the Fick's law for air diffusion combined with the ideal gas law to convert air mass to air volume and concentration differential to matric suction (Fredlund and Rahardjo 1993; Romero, 2001):

$$
\frac{d V_{d}}{d t}=\frac{n A D h\left(u_{a}-u_{w}\right)}{\left(u_{w}+u_{a t m}\right) t_{c}}
$$

where $V_{\mathrm{d}}$ is the volume of accumulated air, $t$ is the time, $n, A$, and $t_{\mathrm{c}}$ are the porosity, cross-sectional area, and thickness disc of the ceramic respectively, $h$ is the volumetric coefficient of solubility $\left(h=0.018\right.$ at $\left.22^{\circ} \mathrm{C}\right), D$ is the air diffusion coefficient through the saturated ceramic disc, $u_{\mathrm{atm}}$ represents the absolute atmospheric pressure, $u_{\mathrm{a}}$ and $u_{\mathrm{w}}$ refer to the air and water gauge pressure, and $u_{\mathrm{a}}-u_{\mathrm{w}}$ 
is the applied matric suction. Equation (6) shows that the rate of accumulation of dissolved air at given matric suction $u_{\mathrm{a}}-u_{\mathrm{w}}$ can be reduced if water pressure in the reservoir $u_{\mathrm{w}}$ is increased, i.e. a back-water pressure is applied.

\subsubsection{High degrees of saturation}

As demonstrated in Figure 10, the basic assumption upon which the axis translation technique has been built states that the water and solid boundaries are sufficiently incompressible to not modify the curvature of the interface upon the application of an elevated air pressure. If the curvature of the menisci remains constant, any change in air pressure is directly translated into an equal increase in pore water pressure. This is valid provided there are no isolated air bubbles in the soil mass. This assumption has been validated by Hilf (1956) and Bishop and Donald (1961), by allowing a sample to come to equilibrium under a specific matric suction $\left(u_{a}-u_{w}\right)$ and then changing the air pressure and measuring the corresponding change in pore water pressure, and Tarantino et al. (2000) in the range of absolute negative pressures.

In general the air pressure is considered to be atmospheric before the axis translation technique is applied. Hilf (1956) suggested that air pressure immediately after compaction may be initially higher than atmospheric but rapidly tends to recover to the atmospheric value. Barden and Sides (1970) infer from experimental data that the occluded air bubbles do not equilibrate rapidly as usually assumed. The coefficient of diffusion of free water is 50 times higher than that occurring in saturated soils. This difference seems to be due to increase in viscosity and tortuosity. This has great implication on the use of axis translation technique.

Bocking and Fredlund (1980) performed a theoretical study evaluating the effect of occluded air during the use of the axis translation technique for measuring suction. The results suggested that the suction is over estimated if the soils have a highly compressible structure. Chahal and Yong (1965) is surprisingly one of the very few studies that has attempted to validate the use of the axis translation technique by using tensiometers in the same apparatus. The expected effect of the use of the axis translation technique is that it may inhibit the formation of nucleation inside the soil. Chahal and Yong (1965) showed that when the pressure plate apparatus is converted into a tensiometer by the reduction of the air pressure to the atmospheric conditions the pore water pressure measured is smaller than the difference between air and water pressure during the axis translation. Lourenço et al. (2006) has more recently noted a similar discrepancy.

One theory to explain this response can be generated by considering again the capillary tube conceptual model. Unlike the capillary tubes discussed earlier in the 
paper, the capillary tube in this discussion (Figure 13a) contains an entrapped air cavity at some elevation below the atmospheric air-water interface dictated by the contact angle $\theta_{0}$. If in the laboratory environment, this same capillary tube was sealed and subjected to an elevated air pressure, the relative high compressibility of the air cavity will lead to a significant reduction in the cavity's volume, the increase in the cavity air pressure being lower than the external air pressure increase. If the gas-liquid-solid junction of the outer meniscus remains fixed, as occurs to the drop on the tilting plate in Figure 2, the curvature of the air-water interface $\theta_{\mathrm{AT}}$ will increase because of the compression of the entrapped air cavity as shown in Figure $13 \mathrm{~b}$, causing the pressure differential between air and water pressure to increase. This is in agreement with the findings of Chahal and Yong (1965). This change in contact angle with applied air pressure is in contrast to the assumptions behind the axis translation technique.

However, if in the long term the external air at elevated pressure would diffuse through the liquid into the air cavity, an equilibrium will be restored. The outer meniscus will recover the original curvature and so will the suction (Figure 13c). In other words, limitations of the axis-translation technique at high degrees of saturation essentially lie on the slow rate of air diffusion to the air cavities.

To avoid the meniscus deformation shown in Figure 13b, the external air pressure can be varied slowly to allow the air to diffuse towards the cavities (Di Mariano, 2000; Romero, 2001). When controlling suction using the axistranslation, an alternative technique is to modify the water pressure while keeping constant the external air pressure. Such a technique is referred to as 'airoverpressure' technique in contrast to the classical 'water-subpressure' technique where air pressure is changed while keeping constant the water pressure (Romero, 2001). Using the air-overpressure technique, deformation associated with the temporary suction increase shown in Figure $13 \mathrm{~b}$ can be avoided. This deformation can also be viewed as generated by the external air pressure which temporarily acts as total stress.

\section{$5 \quad$ Final remarks}

Experimental equipment for the measurement of matric suction in unsaturated soils using tensiometers and the axis translation technique have been shown to share a common working principle; that is, the measurement of a pressure differential across a high air entry ceramic disk. In this paper, the current state of the art in these two suction measurement techniques has been presented and discussed together to underline their similarities in saturation procedures, the need for intimate contact, measurement range, and challenges and limitations associated with air diffusion and 
air entry. Although the advent of the HCT has now permitted direct matric suction measurements to $-1500 \mathrm{kPa}$, the ease of use of the axis translation technique will ensure that both of these techniques will be used to quantify the matric suction of soils in laboratory tests for the foreseeable future.

\section{References}

Alberty, R.A. 1987. Physical chemistry. John Wiley \& Sons

Balibar, S. 2002. Nucleation in quantum liquids. Journal of low temperature physics 129 (56): 363-421.

Barden, L., and Sides, G.R. 1970. Engineering behaviour and structure of compacted clay. Journal of the Soil Mechanics and Foundations Division, ASCE, 96(SM4): 33-51

Berry, R.S., Rice, S.A. \& Ross, J. (1980). Physical chemistry. John Wiley \& Sons

Bishop, A. W. \& Eldin, G. (1950). Undrained triaxial tests on saturated sands and their significance in the general theory of shear strength. Géotechnique 2, No. 1, 13-32.

Bishop, A.W. \& I.B. Donald 1961. The experimental study of partly saturated soil in the triaxial apparatus. Proc. 5th Int. Conf. Soil Mech., Paris 1:13-21.

Brennen, C. E. (1995). Cavitation and Bubble dynamics. Oxford University Press.

Bocking, K.A. and Fredlund, D.G. (1980). Limitation of the axis translation technique. 4th International Conference on Expansive Soils. Vol.1. Colorado. pp.117-135.

Boso, M., Tarantino A. \& Mongiovì, L. 2004. Shear strength behaviour of a reconstituted clayey silt. Advances in testing, modelling and engineering applications, C. Mancuso \& A. Tarantino (eds), Proc. of an International Workshop, Anacapri, 22-24 June 2004, 114. Rotterdam: Balkema.

Chahal, R.S. and Yong, R. N. (1965). Validity of the soil water characteristic determined with the pressurized apparatus. Soil Science. Vol. 99, n. 2. pp 98-103.

Cunningham, M. R., Ridley, A. M., Dineen, K. and Burland, J. B. (2003). The mechanical behaviour of a reconstituted unsaturated silty clay. Géotechnique, 53: 183-194

De Benedetti, P.G. (1996) Metastable liquids. Princeton University Press.

Di Mariano, A. (2000). Le argille a scaglie e il ruolo della suzione sulla loro deformabilità. $\mathrm{PhD}$ Thesis, Università di Palermo e di Catania.

Druck, 2005. Personal communication

Fourie, A. B. and Papageorgiou, G. (1995). A technique for the rapid determination of the moisture retention relationship and hydraulic conductivity of unsaturated soils. 1st International Conference on Unsaturated Soils. Paris. Vol 1. pp. 485-490.

Fredlund, D.G. and Rahardjo, H. (1993). Soil mechanics for unsaturated soils. WileyInterscience Publications.

Gee, G. W. Ward, A. L. Zhang, Z. F., Campbell, G. S. and Mathison, J. (2002). The Influence of Hydraulic Nonequilibrium on Pressure Plate Data. Vadose Zone Journal 1:172-178 (2002).

Gibbs, J.W. (1948). The collected works of J. Willard Gibbs. Volume 1: Thermodynamics. Yale University Press.

Guan, Y. \& D.G. Fredlund 1997. Use of tensile strength of water for the direct measurement of high soil suction. Canadian Geotechnical Journal 34: 604-614.

Harvey, E.N., Barnes, D.K., McElroy, W.D., Whiteley, A.H. Pease, D.C. \& Cooper, K.W. 1944. Bubble formations in animal, 1- Physical Factor. J. Cellular and Comparative Physiology, 24(1): 1-22. 
Hilf, J.W. (1956). An investigation of pore-water pressure in compacted cohesive soils. Ph.D. thesis, Technical Memorandum 654, U.S. Department of the Interior Bureau of Reclamation, Denver, Colorado.

Johnson, R.E. and Detre R.H. (1969). Wettability and contact angles. In Surface and Colloid Science, E. Matijevic and F.R. Eirich (eds.), vol. 2, pp. 85-152. John Wiley \& Sons.

Knapp, R.T.; Daily, J.W. and Hammit, F.G. (1970). Cavitation. McGraw-Hill Book Company.

Knight, M. A. and Kotha, S. M. (2001). Measurement of geotextile-water characteristic curves using a controlled outflow capillary pressure cell. Geosynthetics International. Vol. 8. n. 3. pp 271-282.

Leong, E. C., Tripathy, S; Rahardjo, H.(2004). A Modified Pressure Plate Apparatus. Geotechnical Testing Journal. 27 (3). 322-331.

Lorentz, S. A., DurnFord, D. S. and Corey, A. (1993). Liquid retention measurement on porous media using a controlled outflow cell. Proceedings of American Society of Agronomy - Crop Science Society of America - Soil Science Society of America 1991 annual meeting. Denver, Colorado.

Lourenço, S.D.N., Gallipoli, D., Toll, D.G., and Evans, F.D., 2006, "Development of a commercial tensiometer for triaxial testing of unsaturated soils" In Proceedings 4th International Conference on Unsaturated Soils, Phoenix, Geotechnical Special Publication 147 (eds. G.A. Miller, C.E. Zapata, S.L. Houston and D.G. Fredlund) Reston: ASCE, Vol.2, pp. 1875-1886.

Lowe, J. and Johnson, T.C. 1960. User of back-pressure to increase degree of saturation of triaxial test specimens. ASCE research conference on shear strength of cohesive soils, Bolder, Colorado. 819-836.

Machado, S. L. and Dourado, K. A. (2001). New Techniques for determining the Soil Water characteristic curve for soils. 4th Brazilian Symposium on Unsaturated Soils. Porto Alegre. Vol 1 . pp 325-336. (In Portuguese)

Marinho, F.A.M. and Chandler, R.J. 1994. Discussion: A new instrument for the measurement of soil moisture suction. Géotechnique 44(3): 551-556.

Marinho and Pinto (1997). Soil suction measurement using a tensiometer. Symposium on Recent Development in Soil and Pavement Mechanics - Rio de Janeiro, June. pp. 249254.

Mongiovì, L. \& A. Tarantino 2002. Pore water pressure measurement in unsaturated soils. Proc. International Workshop on "Clay behaviour: chemo-mechanical coupling", Maratea, Italy, June 2001: 233-246. Rotterdam: A. A. Balkema.

Oliveira, O.M., and Marinho, F.A.M. (2003). Unsaturated Shear Strength Behaviour of a Compacted Residual Soil. In Second Asia Conference on Unsaturated Soils, Osaka, $1: 237-242$.

Oliveira, O.M., and Marinho, F.A.M. (2008). Suction equilibration time for a high capacity tensiometer. Submitted for publication. Geotechnical Testing Journal, 31(1): 1-5.

Olson, R. E. and Langfelder, L. J. (1965). Pore water pressure in saturated soils. Journal of the soil mechanics and foundation division - ASCE. July, SM4. pp. 127-150.

Richards, L. A. (1941). A pressure-membrane extraction apparatus for soil solution. Soil Science. Vol 51, n5. pp. 377-386.

Richards, L. A. (1947). Pressure-membrane apparatus - Construction and use. Agricultural Engineering. Pp.451-460.

Richards, L.A. and Weaver L.R. (1944). Moisture retention by some irrigated soils as related soil- moisture tension. Journal of Agricultural Res. 69:215-235. 
Ridley, A.M. (1993) The measurement of soil moisture suction. Ph.D. Thesis, University of London

Ridley, A.M. \& Burland, J.B. (1993). A new instrument for the measurement of soil moisture suction. Géotechnique, v.43,n.2, 321-324

Ridley, A.M. and Burland, J.B. 1995. Measurement of suction in materials which swell. Applied Mechanics Reviews, 48(9): 727-732

Ridley, A. M. \& Burland, J. B. 1999. Discussion: Use of tensile strength of water for the direct measurement of high soil suction. Canadian Geotechnical Journal, 36, 178-180.

Ridley, A.M. \& Wray, W.K, 1996. Suction measurement: a review of current theory and practices. In Unsaturated Soils, Alonso and Delage (eds)

Ridley, A.M., Schnaid, F., da Silva, G.F:, and Bica, A.V.D., 1997. In situ suction measurements in a residual soil of southern Brasil. In NSAT'97-3 $3^{\circ}$ Simpósio Brasileiro sobre Solos Não Saturados, Rio de Janeiro, Brasil, T.M.P. de Campos and E.A. Vargas Jr. Freitas Bastos (eds), 2, pp. 537-542.

Romero, E. (1999) "Characterisation and thermo-hydromechanical behaviour of unsaturated Boom Clay: an experimental study", $\mathrm{PhD}$ Thesis, Universitad Politecnica de Cataluna.

Romero E. (2001). Controlled-suction techniques. $4^{\circ}$ Simpósio Brasileiro de Solos Nâo Saturados Ñ SAT’2001, W.Y.Y. Gehling \& F. Schnaid (eds), PortoAlegre, Brasil, 2001, pp. 535-542.

Rowlinson J.S. (1988). J.D. van der Waals: On the continuity of the gasesous and liquid states. North-Holland.

Schreiner, H. D. (1988). Volume change of compacted highly plastic African clays $-\mathrm{PhD}$ thesis - Imperial College - 313p.

Sjoblom, K.J. 2000. The mechanisms involved during the desaturation process of a porous matrix. PhD Dissertation, Massachusetts Institute of Technology, Boston, US.

Stannard, D.I. (1992). Tensiometers - Theory, construction, and use. Geotechnical Testing Journal, v.15, n.1, 48-58

Take, W.A. 2003. The influence of seasonal moisture cycles on clay slopes. Univ. of Cambridge $\mathrm{PhD}$ dissertation, Cambridge, UK.

Take, W.A., and Bolton, M.D. (2003). Tensiometer saturation and the reliable measurement of matric suction. Geotechnique 53(2):159-172.

Take, W. A. \& Bolton, M. D. (2004). Discussion: Geotechnique 54, No. 3, 229-232

Tarantino, A. 2004. Panel Lecture: Direct measurement of soil water tension. Proc. 3rd Int. Conf. on Unsaturated Soils, Recife, Brasil, 3: 1005-1017.

Tarantino, A. \& L. Mongiovì 2000. Experimental investigations on the stress variables governing unsaturated soil behaviour at medium to high degrees of saturation. In A. Tarantino and C. Mancuso (eds), Experimental Evidence and Theoretical Approaches in Unsaturated Soils: 3-19. Rotterdam: A.A. Balkema.

Tarantino A, Mongiovì L 2001. Experimental procedures and cavitation mechanisms in tensiometer measurements. Geotechnical and Geological Engineering 19 (3-4): 189-210.

Tarantino, A. \& Mongiovì, L. (2002). Design and construction of a tensiometer for direct measurement of matric suction. Proc. 3rd Int. Conf. on Unsaturated Soils, Recife 1, 319-324.

Tarantino, A. \& Tombolato, S. (2005). Coupling of hydraulic and mechanical behaviour in unsaturated compacted clay. Géotechnique, 55(4), 307-317.

Toker, N.K. 2002. Improvements and reliability of MIT tensiometers and studies on soil moisture characteristic curves. MSc Dissertation, Massachusetts Institute of Technology, Boston, US. 
Marinho, F.A.M., Take, W.A., and Tarantino, A. State of the art report: tensiometers and axis-translation technique

Submitted to Geotechnical and Geological Engineering

Special Issue on "Laboratory and Field Testing of Unsaturated Soils"

Vanapalli SK, Sharma RS Nicotera MV (2008). Axis-translation and negative water column techniques for suction control. Geotechnical and Geological Engineering, this issue.

Wang, X. and Benson, C. (2004), Measuring the Soil Water Characteristic Curve with the Leak-Free Pressure Plate Extractor, Geotech. Testing J., ASTM, 27(2), 1-10.

Whalley, W.R., Clark, L.J., Take, W.A, Bird, N.R.A., Leech, P.K., Cope, R.E. and Watts C.W. 2006. A porous-matrix sensor to measure the matric potential of soil water in the field. European Journal of Soil Science. Online publication date: 3-Mar-2006

Zheng, Q, Durben, D.J., Wolf, G.H., and Angell, C.A. 1991. Liquids at large negative pressures: water at the homogeneous nucleation limit. Science, Vol. 254, No. 5033 (Nov. 8, 1991), 829-832. 
a)

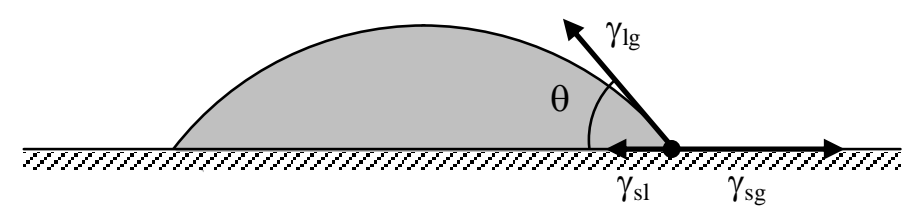

b)

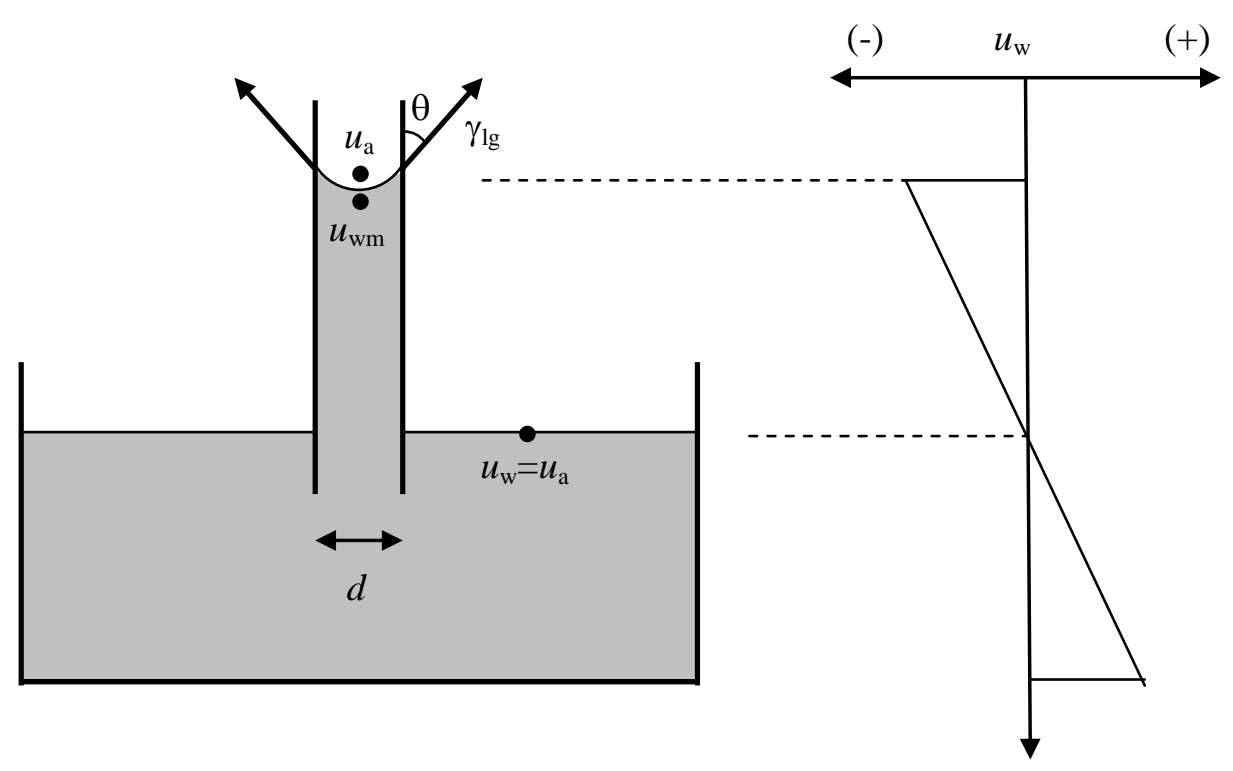

Figure 1. a) contact angle for an ideal smooth, homogenous and non-deformable surface $(\gamma=$ surface tension, $s l=$ solid-liquid, $s g=$ solid-gas, $l g=$ liquid-gas $) . b$ ) capillary rise of wetting fluid. 
a)

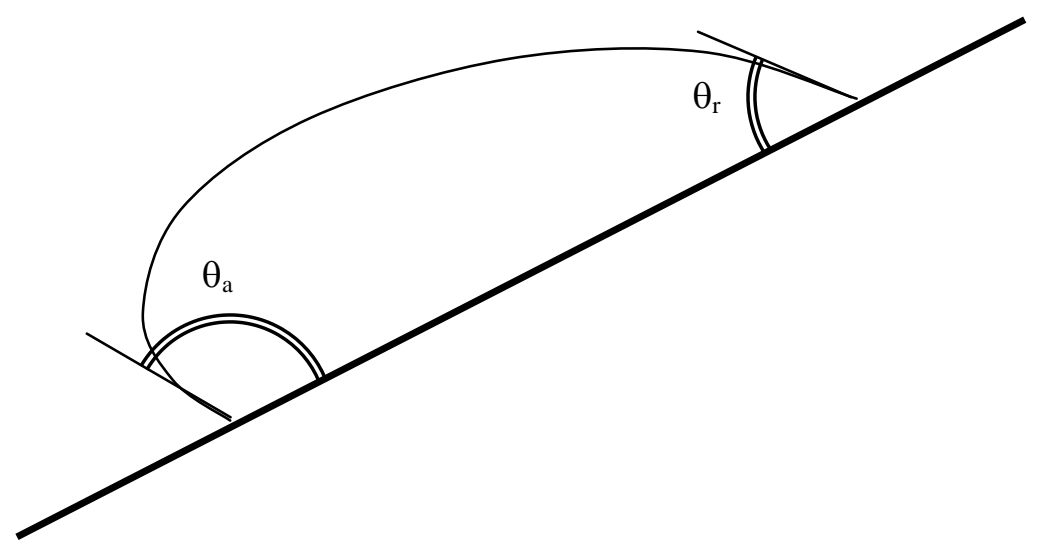

b)

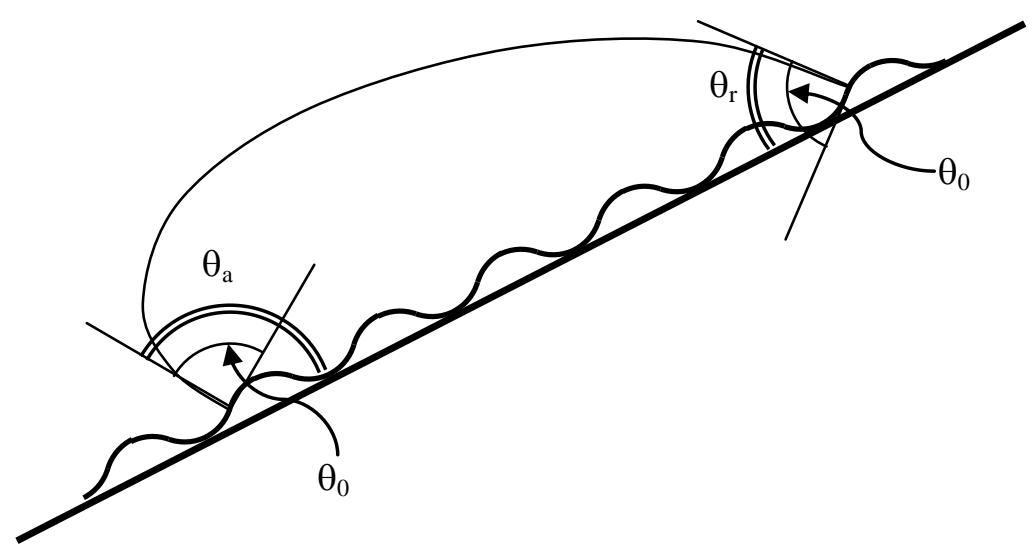

c)

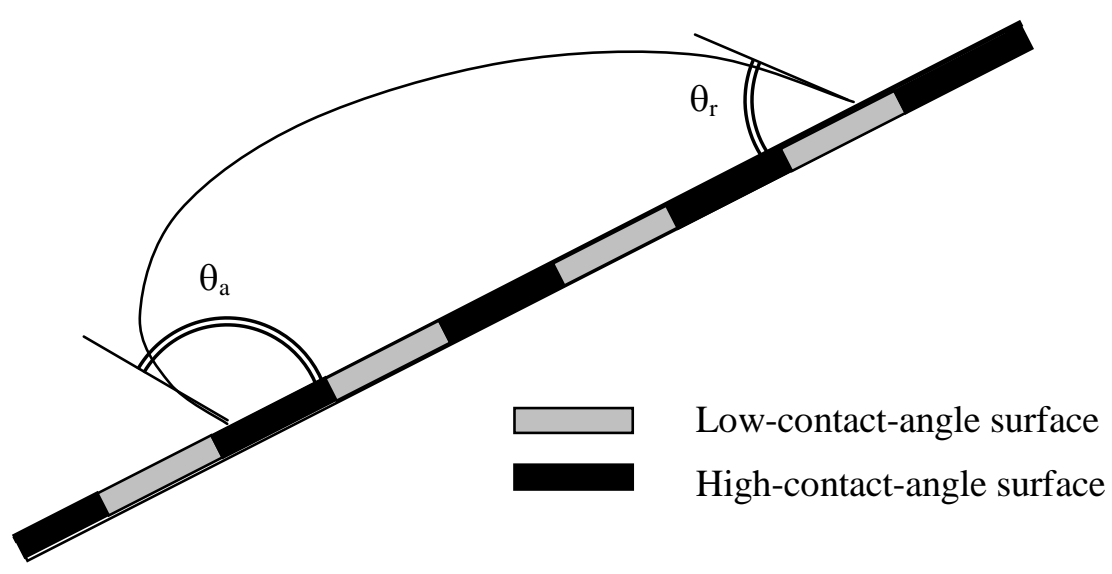

Figure 2. Hysteresis of contact angle for real surfaces (after Johnson and Dettre, 1969. a) Water drop on a tilted surface. b) Effect of roughness on hysteresis. c) Effect of heterogeneity on hysteresis). 


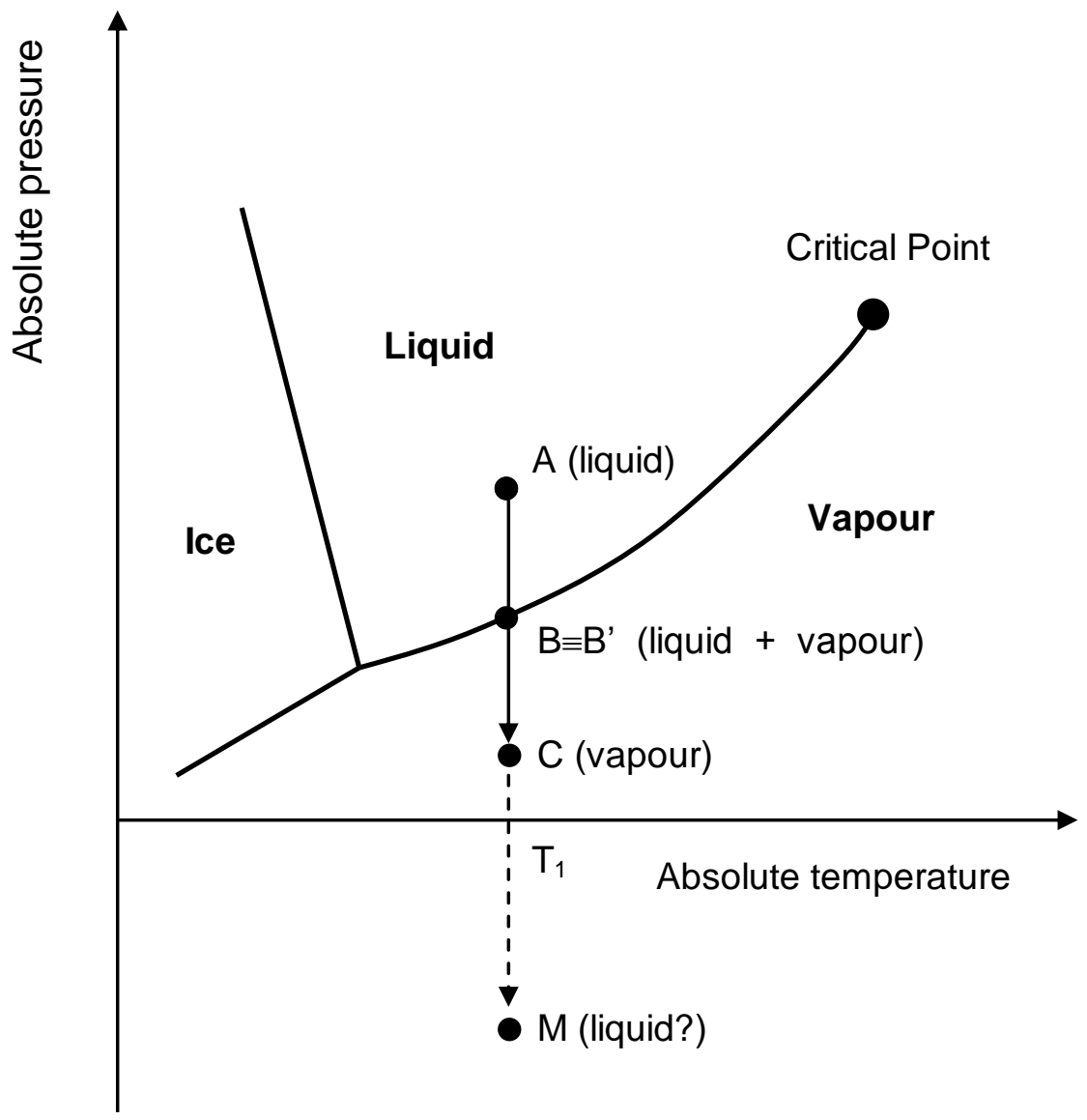

Figure 3. Phase diagram for water 


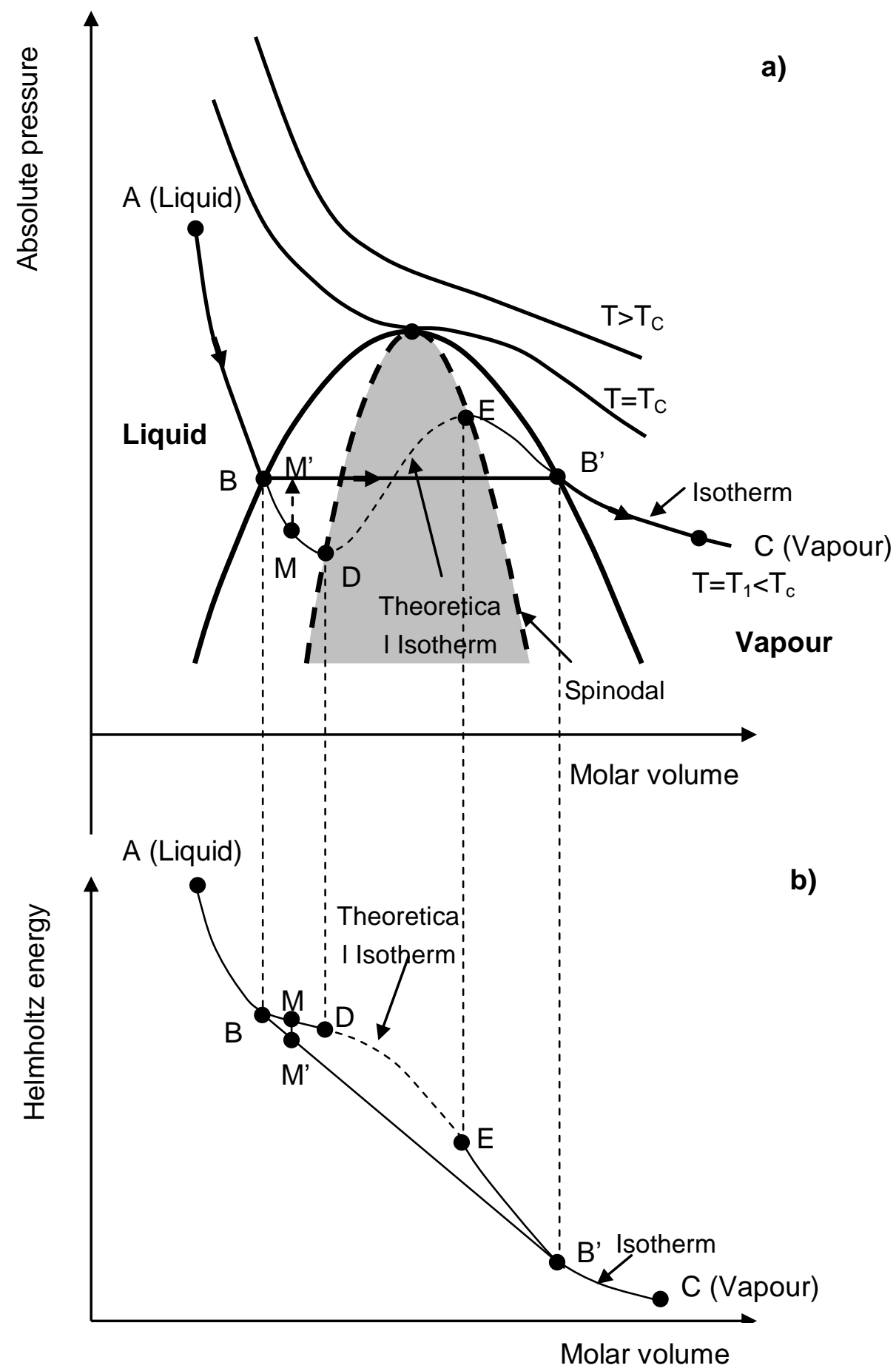

Figure 4. Isotherms in the pressure-partial volume plane and Helmoltz energy of vapour and liquid water at constant temperature $\left(T_{\mathrm{c}}=\right.$ critical temperature $)$. 
Marinho, F.A.M., Take, W.A., and Tarantino, A. State of the art report: tensiometers and axis-translation technique Submitted to Geotechnical and Geological Engineering Special Issue on "Laboratory and Field Testing of Unsaturated Soils"

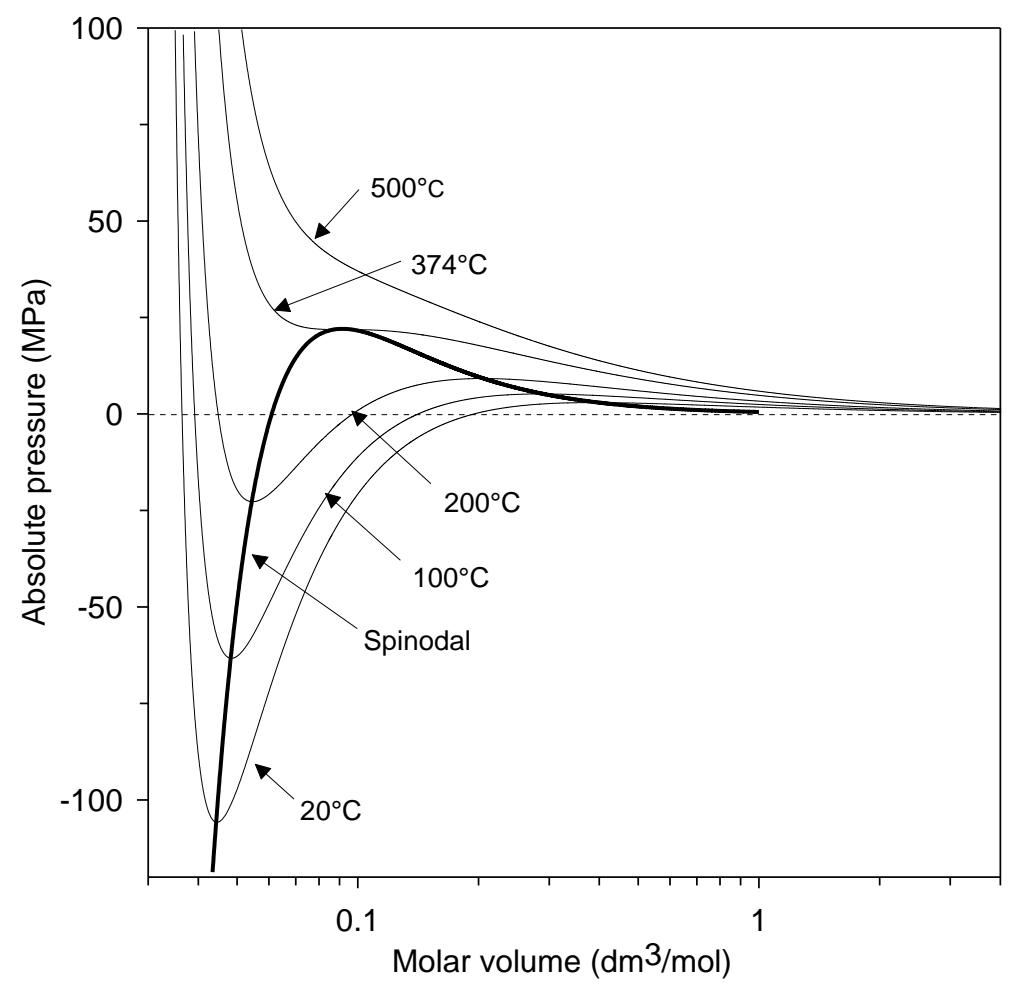

Figure 5. Van der Waals isotherms for water in the absolute pressure-partial volume plane. 


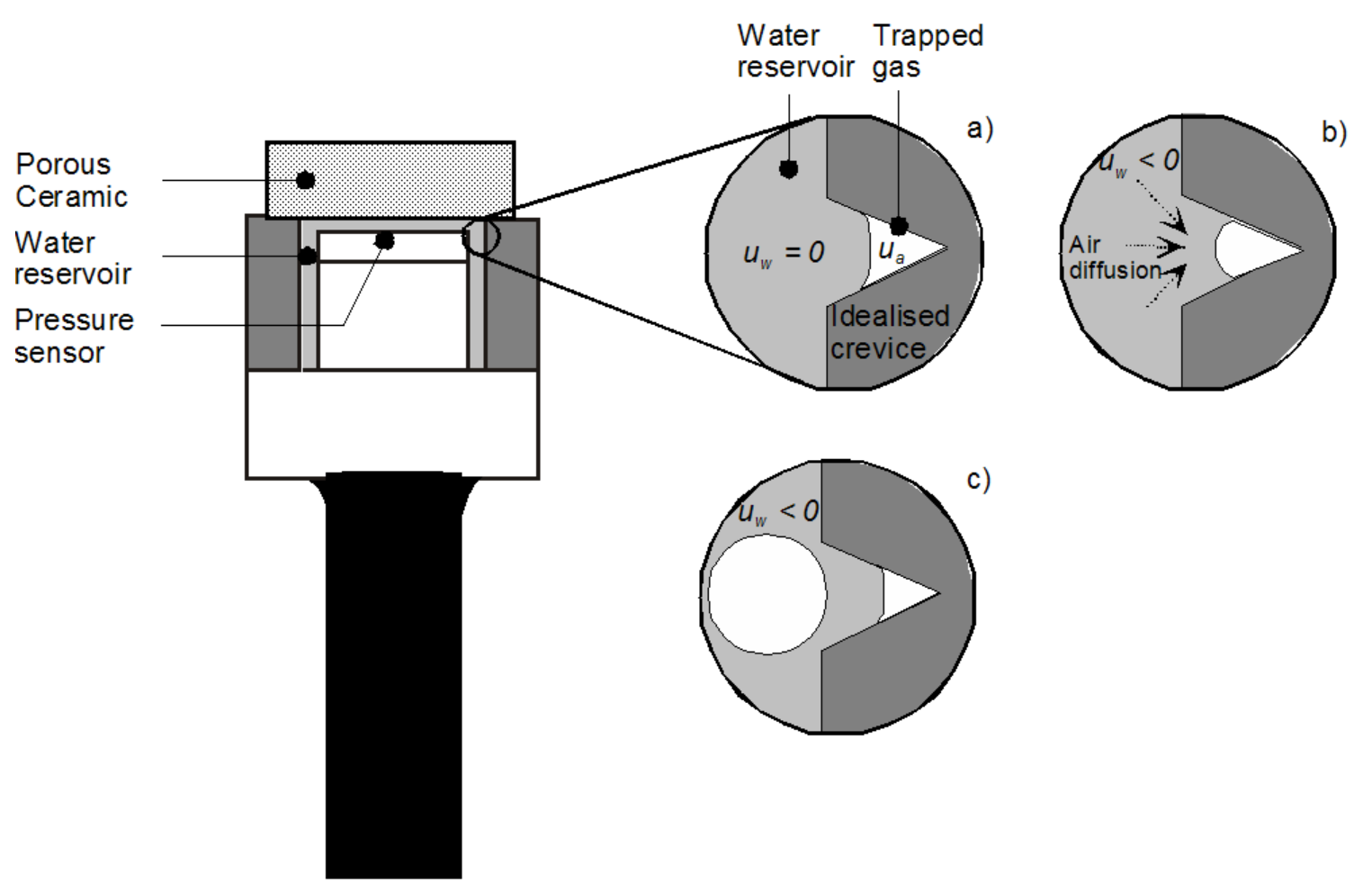

Figure 6.The crevice model of heterogeneous nucleation 


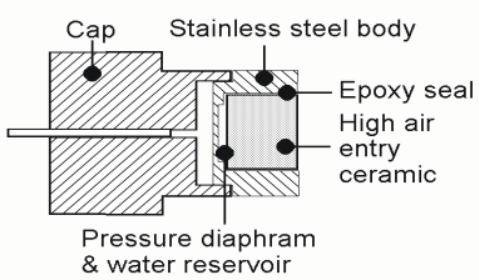

(Ridley and Burland, 1995)

Entran EPX transducer

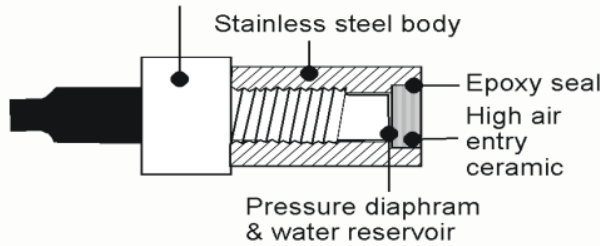

(Ridley and Burland, 1995; Marinho and Pinto, 1997)

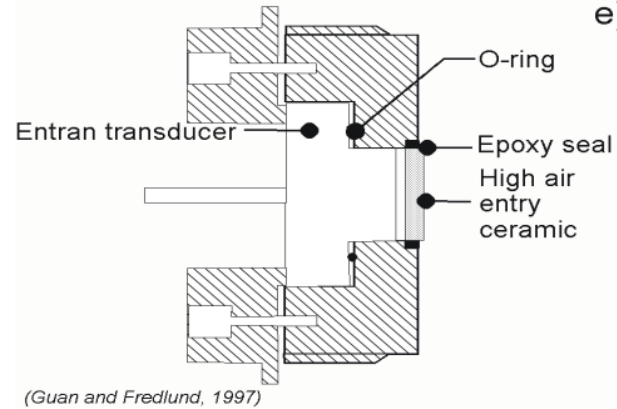

e)

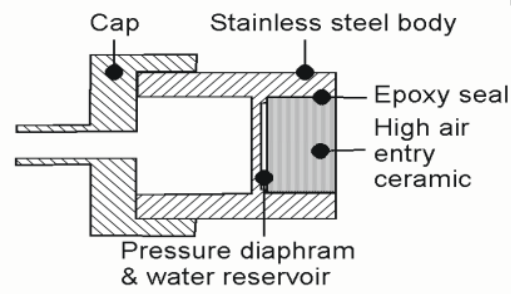

b)

(Tarantino and Mongiovi, 2002)

c)

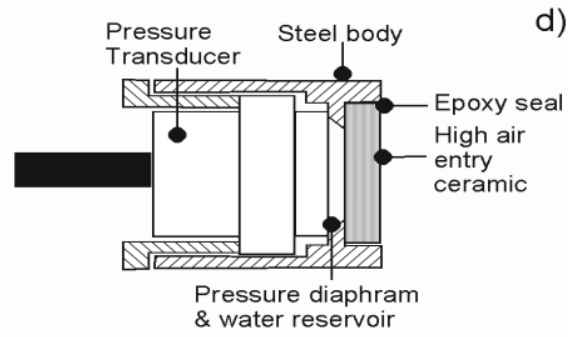

(Toker, 2002)

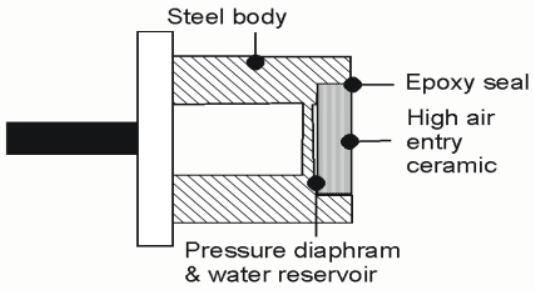

(Sjoblom, 2000)

g)

h)

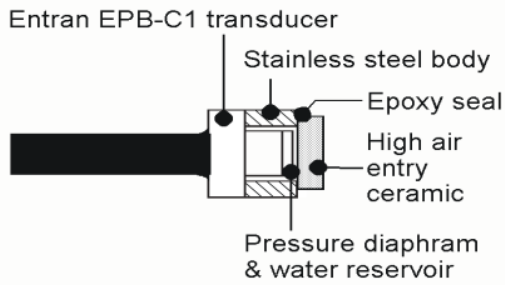

(Take and Bolton, 2003)
(Druck, 2005)

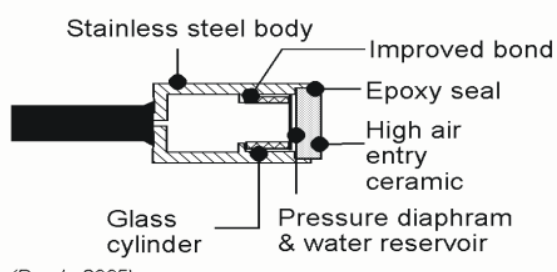

i)

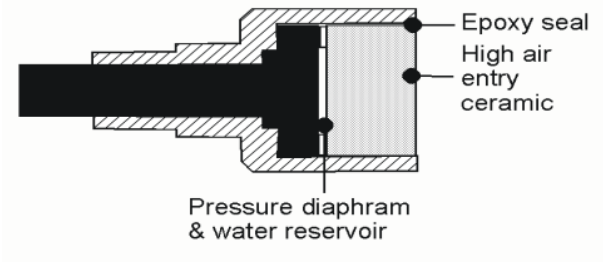

(Lourenço et al., 2006)

Figure 7.High capacity tensiometers reported in the literature. 
Marinho, F.A.M., Take, W.A., and Tarantino, A. State of the art report: tensiometers and axis-translation technique Submitted to Geotechnical and Geological Engineering

Special Issue on "Laboratory and Field Testing of Unsaturated Soils"

water

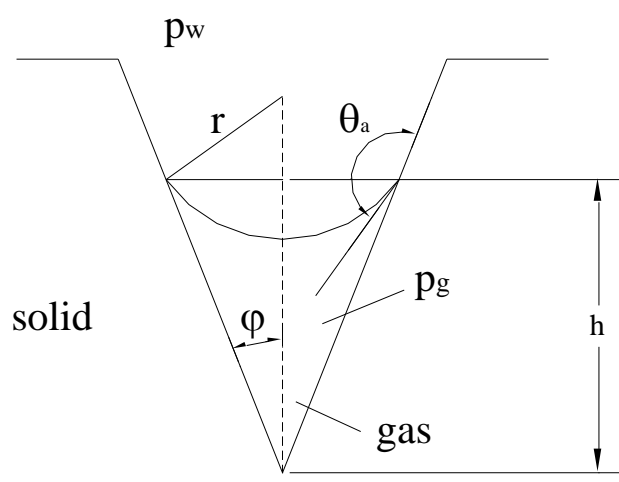

(a) water

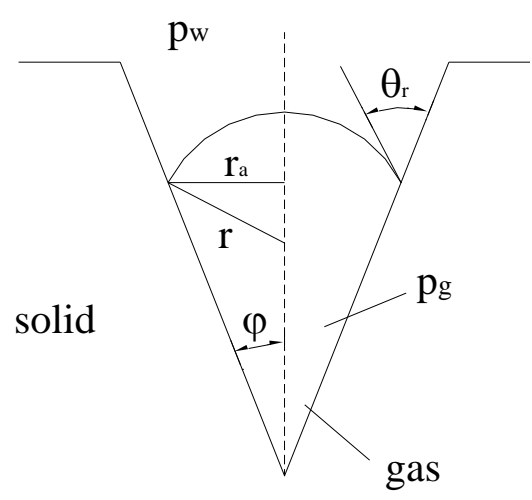

(b)

Figure 8. Idealised conical crevice. (a) Gas cavity subjected to positive pressure. (b) cavity subjected to negative pressure. 


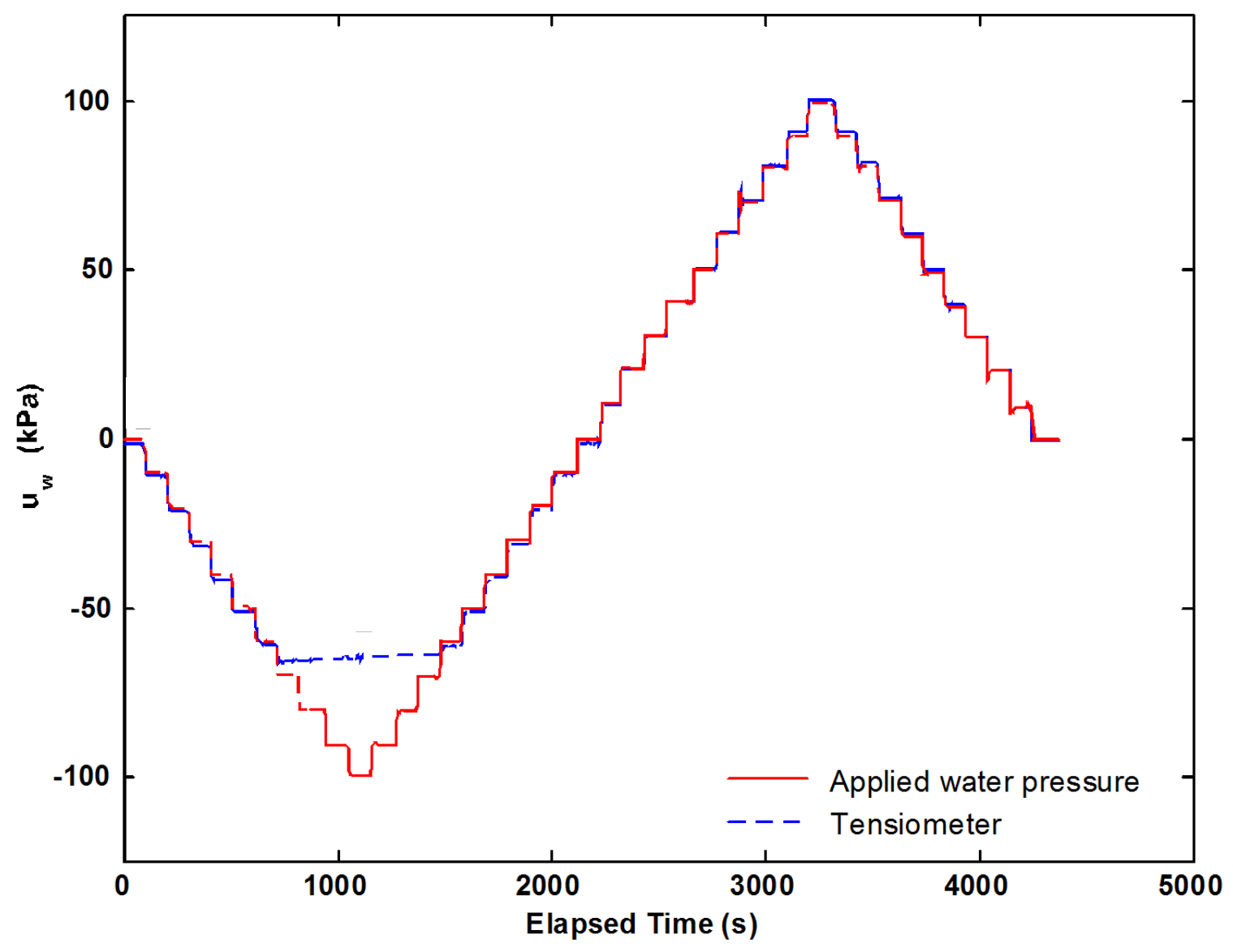

Figure 9. Challenge of interpreting tensiometer data (Take and Bolton, 2003) 


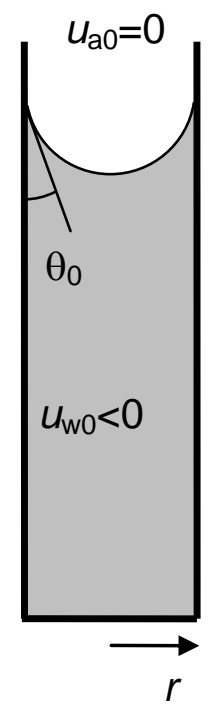

a)

a)

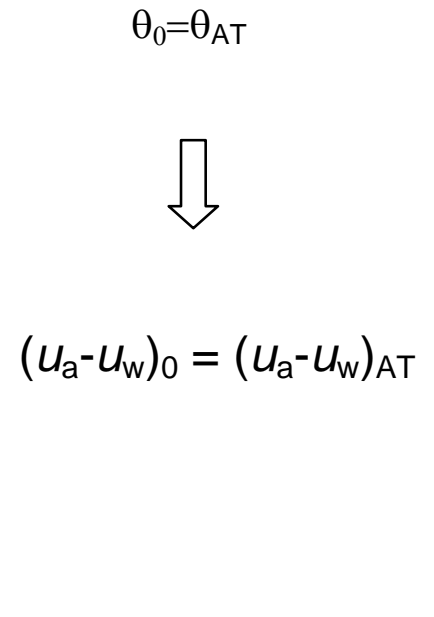

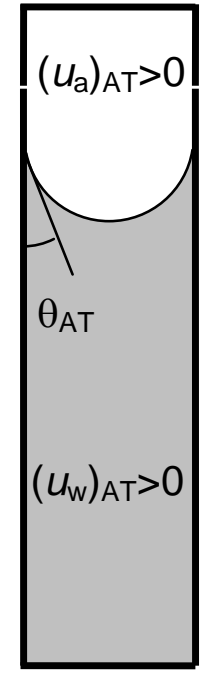

b)

Figure 10.Working principle of axis translation technique 

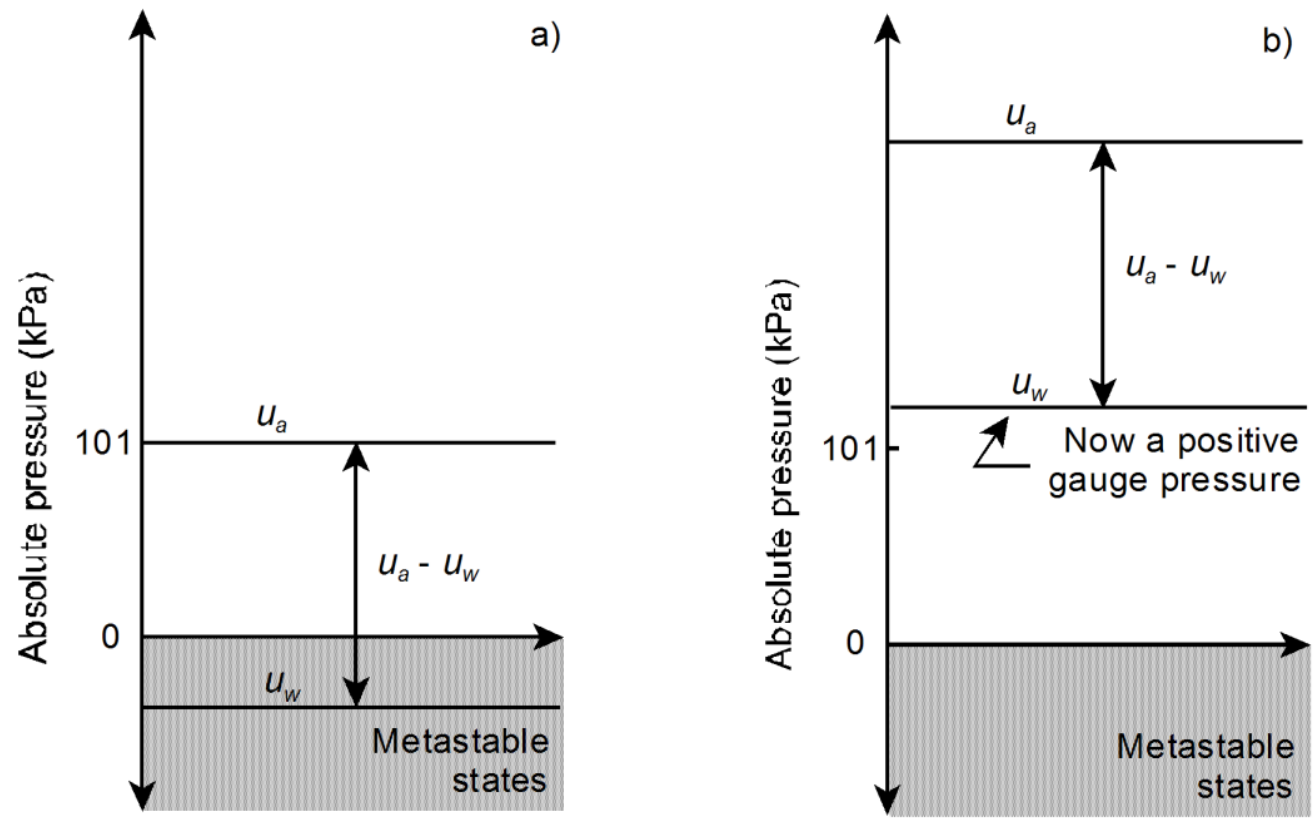

Figure 11. Use of the axis translation technique to avoid metastable states 
Marinho, F.A.M., Take, W.A., and Tarantino, A. State of the art report: tensiometers and axis-translation technique

Submitted to Geotechnical and Geological Engineering

Special Issue on "Laboratory and Field Testing of Unsaturated Soils"

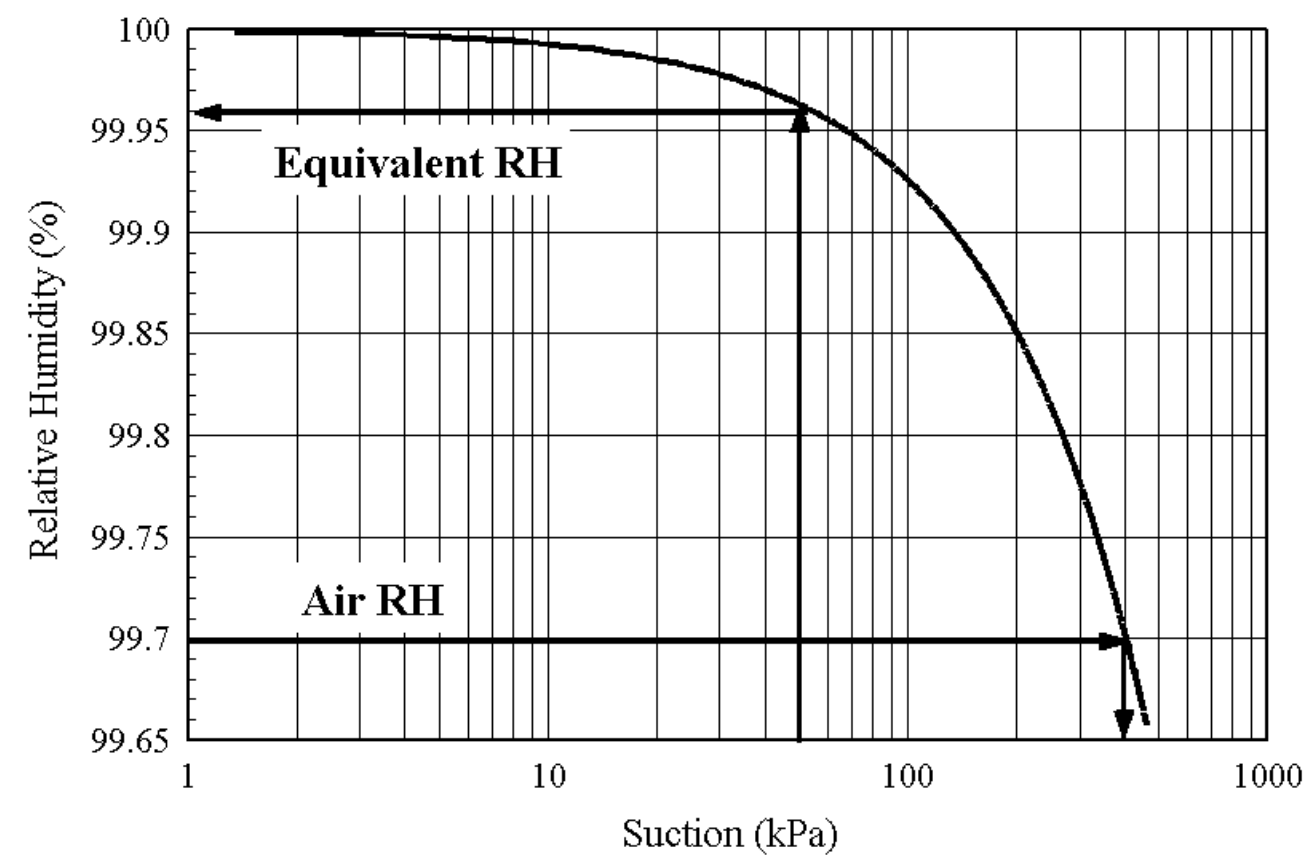

Figure 12 - Thermodynamic relation between suction and relative humidity and the eventual difference between applied suction and the equivalent suction of the air. 
Short term

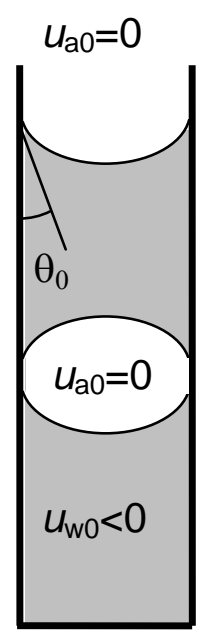

(a)

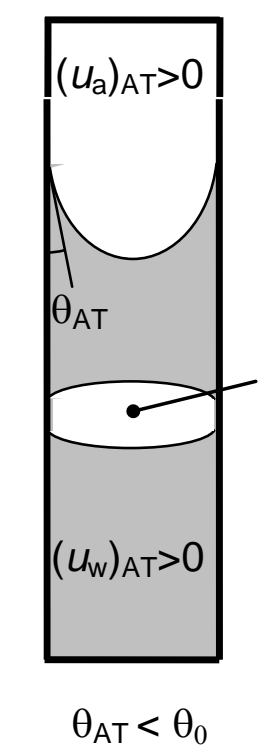

$u_{\mathrm{a}}<\left(u_{\mathrm{a}}\right)_{\mathrm{AT}}$

$u_{\mathrm{a}}=\left(u_{\mathrm{a}}\right)_{\mathrm{AT}}$

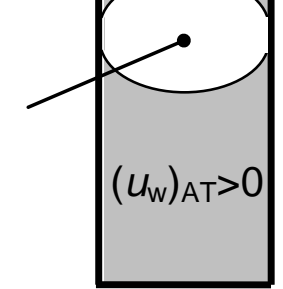

$\theta_{\mathrm{AT}}=\theta_{0}$

$\left(u_{\mathrm{a}}-u_{\mathrm{w}}\right)_{\mathrm{AT}}=\left(u_{\mathrm{a}}-u_{\mathrm{w}}\right)_{0}$

$$
\left(u_{\mathrm{a}}-u_{\mathrm{w}}\right)_{\mathrm{AT}}>\left(u_{\mathrm{a}}-u_{\mathrm{w}}\right)_{0}
$$

(c)

Figure 13. Working principle of axis translation technique in presence of occluded air. (a) Negative water pressure. (b) Positive water pressure in the short term. (c) Positive water pressure in the long term. 